Keywords: stainless steel, surface chemistry, surface treatment, electropolishing

Retention: Permanent

\title{
Analysis of Passivated Surfaces for Mass Spectrometer Inlet Systems by Auger Electron and X-Ray Photoelectron Spectroscopy
}

H.M. Ajo, D. W. Blankenship, E. A. Clark

September 2010

Savannah River National Laboratory Savannah River Nuclear Solutions, LLC Aiken, SC 29808

Prepared for the U.S. Department of Energy under contract number DE-AC09-08SR22470.

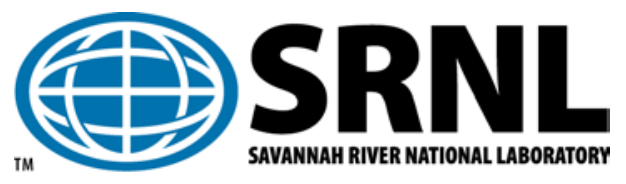


SRNL-STI-2010-00394

Revision 0

\section{DISCLAIMER}

This work was prepared under an agreement with and funded by the U.S. Government. Neither the U.S. Government or its employees, nor any of its contractors, subcontractors or their employees, makes any express or implied:

1. warranty or assumes any legal liability for the accuracy, completeness, or for the use or results of such use of any information, product, or process disclosed; or

2. representation that such use or results of such use would not infringe privately owned rights; or

3. endorsement or recommendation of any specifically identified commercial product, process, or service.

Any views and opinions of authors expressed in this work do not necessarily state or reflect those of the United States Government, or its contractors, or subcontractors.

\section{Printed in the United States of America \\ Prepared for \\ U.S. Department of Energy}




\section{EXECUTIVE SUMMARY}

Stainless steel coupons approximately 0.5 " in diameter and 0.125 ” thick were passivated with five different surface treatments and an untreated coupon was left as a control. These surface treatments are being explored for use in tritium storage containers. These coupons were made to allow surface analysis of the surface treatments using well-know surface analysis techniques. Depth profiles using Auger electron spectroscopy (AES) and X-ray photoelectron spectroscopy (XPS) were performed on these coupons to characterize the surface and near surface regions. Scanning electron microscope (SEM) images were collected as well. All of the surface treatments studied here appear to change the surface morphology dramatically, as evidenced by lack of tool marks on the treated samples. In terms of the passivation treatment, Vendors A-D appeared to have oxide layers that were very similar in thickness to each other (0.7-0.9 nm thick) as well as the untreated samples (the untreated sample oxide layers appeared to be somewhat larger). Vendor E's silicon coating appears to be on the order of $200 \mathrm{~nm}$ thick. 


\section{TABLE OF CONTENTS}

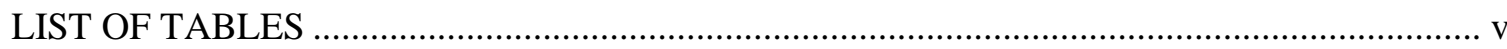

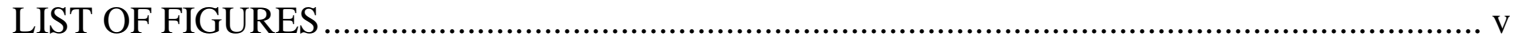

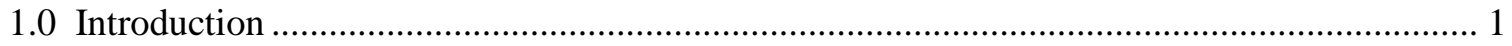

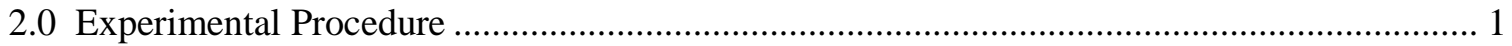

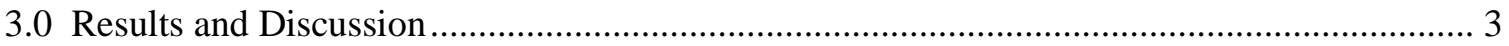

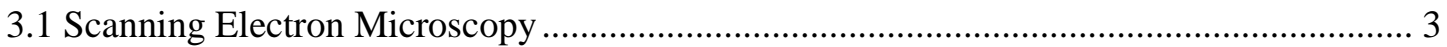

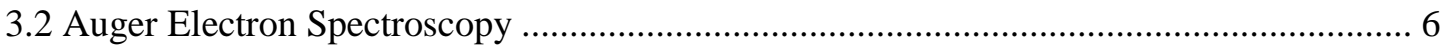

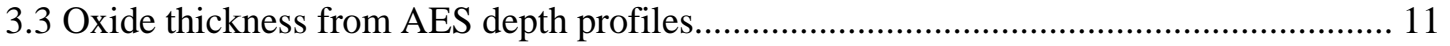

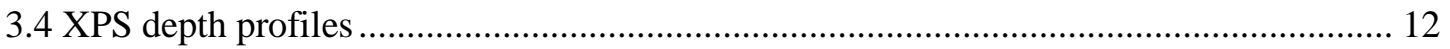

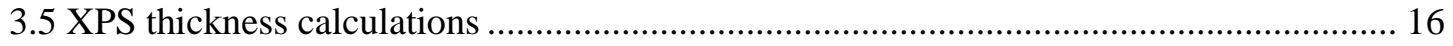

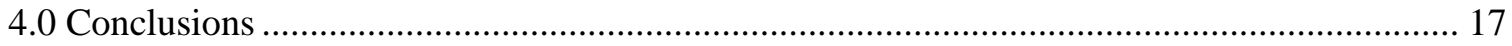

5.0 Recommendations, Path Forward or Future Work ............................................................... 17

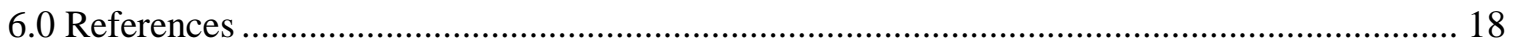




\section{LIST OF TABLES}

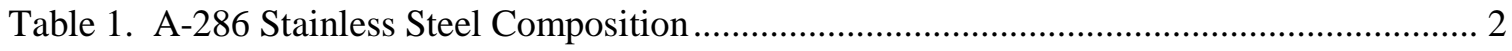

Table 2. AES depth profile oxide thickness calculation......................................................... 12

Table 3. Calculated adventitious carbon and $\mathrm{Cr}_{2} \mathrm{O}_{3}$ thicknesses for Vendors B, C, and D......... 17

\section{LIST OF FIGURES}

Figure 3-1. SEM image of untreated stainless steel coupon...................................................... 3

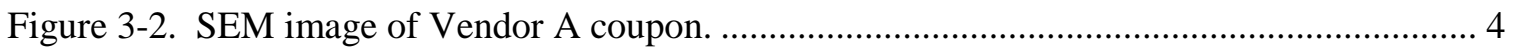

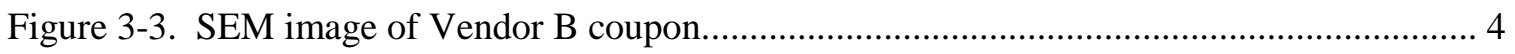

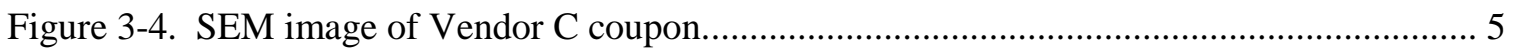

Figure 3-5. SEM image of Vendor D coupon. ........................................................................ 5

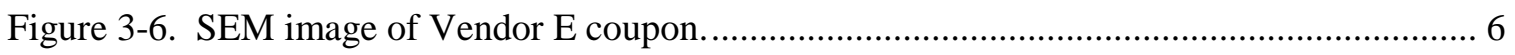

Figure 3-7. SEM image of Vendor E coupon showing chipped surface. …................................... 6

Figure 3-8 AES survey of the untreated stainless steel surface.................................................. 7

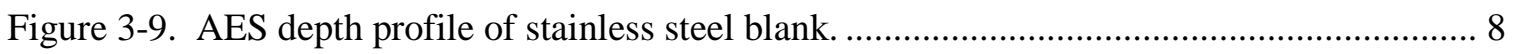

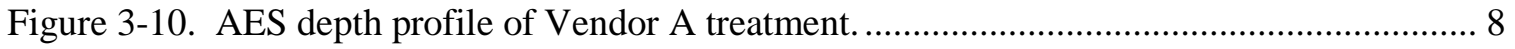

Figure 3-11. AES depth profile of Vendor B coupon................................................................ 9

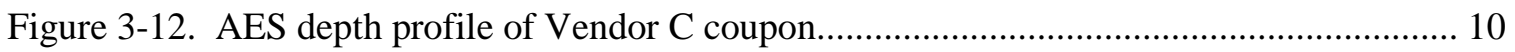

Figure 3-13. AES depth profile of coupon treated by Vendor D............................................... 10

Figure 3-14. AES depth profile of coupon treated by Vendor E................................................ 11

Figure 3-15. XPS survey of Vendor C coupon sputtered down to bulk stainless steel. ................ 12

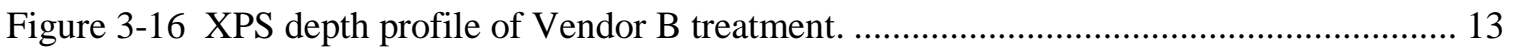

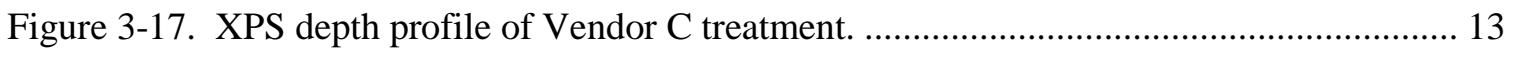

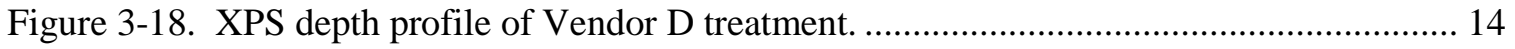

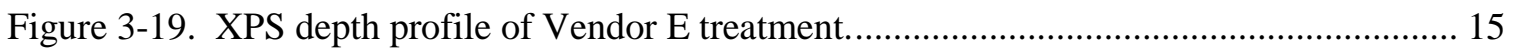

Figure 3-20. XPS depth profile of Vendor treated coupon showing change from $\mathrm{Cr}_{2} \mathrm{O}_{3}$ to $\mathrm{Cr}$

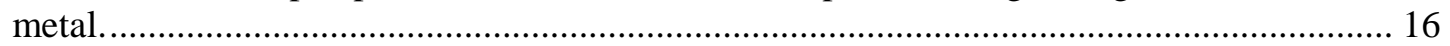




\section{LIST OF ABBREVIATIONS}

$\begin{array}{ll}\text { AES } & \text { Auger electron spectroscopy } \\ \text { SEM } & \text { Scanning electron microscope } \\ \text { SRNL } & \text { Savannah River National Laboratory } \\ \text { XPS } & \text { X-ray photoelectron spectroscopy }\end{array}$




\subsection{Introduction}

The surfaces of components of mass spectrometer inlet systems in the Savannah River Site Tritium Facilities are "passivated". This "passivation" process prevents impurities in the steel, such as carbon and hydrogen, from entering the gas being analyzed. Also, stainless steel surfaces can catalyze gas phase hydrogen isotope exchange and the passivation process likely hinders this catalysis as well. Only two surface passivation vendors are currently used for new components, so it is desirable to seek other commercially available surface treatments that perform as well as the two currently used processes. This Plant Directed Research and Development task is evaluating four commercial surface treatments different from what is used now; three are specifically stainless steel passivation/electropolishing treatments and the fourth is a chemical-vapor deposited (CVD) silicon coating. Results of testing the gas purity level in containers filled with tritium that were coated using the same five methods and vendors will be reported elsewhere.

In the part of this study reported here, flat Type A-286 stainless steel coupons were processed by each of the four candidate passivation or coating treatments, and a fifth coupon using the current vendor's surface treatment is being characterized as the control. The surface chemical composition was investigated using Auger electron spectroscopy (AES) and X-ray photoelectron spectroscopy (XPS). These modern analytical techniques investigate the chemical composition and properties very near to the surface of the sample, and both use argon ion sputtering to remove material at the surface to investigate the chemical composition and structure variation with depth in the sample. AES employs an electron beam impinging the sample surface that interacts with surface atoms; so-called Auger electrons are released from the sample and they are detected by a spectrometer designed for this purpose. The Auger electron spectrum is characteristic of the types of atoms and their composition within $0.5 \mathrm{~nm}$ of the surface of the sample. XPS employs an Xray beam impinging on the surface that ionizes atoms, and the energy spectrum of the ejected atomic electrons is analyzed and is characteristic of the elements and the valence states of the atoms at or near the surface.

\subsection{Experimental Procedure}

Stainless steel (Table 1) coupons, Type A-286, approximately 0.5” in diameter and 0.125” thick were passivated with five different surface treatments: the current vendor surface treatment, electropolishing by three different vendors, and a chemical vapor deposited silicon coating. 
Table 1. A-286 Stainless Steel Composition

\begin{tabular}{|l|c|c|}
\hline \multicolumn{1}{|c|}{ Element } & Min Atomic \% & Max Atomic \% \\
\hline $\begin{array}{l}\text { Iron, } \\
\text { Remainder }\end{array}$ & 59.5 & 48.16 \\
\hline Nickel & 24.00 & 27.00 \\
\hline Chromium & 13.50 & 16.00 \\
\hline Titanium & 1.90 & 2.35 \\
\hline Manganese & - & 2.00 \\
\hline Molybdenum & 1.00 & 1.50 \\
\hline Cobalt & - & 1.00 \\
\hline Silicon & - & 1.00 \\
\hline Vanadium & 0.10 & 0.50 \\
\hline Aluminum & - & 0.35 \\
\hline Carbon & - & 0.08 \\
\hline Phosphorus & - & 0.025 \\
\hline Sulfur & - & 0.025 \\
\hline Boron & 0.003 & 0.010 \\
\hline \hline
\end{tabular}

Depth profiles using Auger electron spectroscopy (AES) and X-ray photoelectron spectroscopy (XPS) were performed on these coupons to characterize the surface and near surface regions. Scanning electron microscope (SEM) images were collected as well using the AES instrument. Since the nature of these surface treatments is proprietary, the vendor treatments are referred to as Vendor A-E.

A Physical Electronics (PHI) 700 Nanoprobe was used to perform the depth profiling using AES. SEM images were collected using this instrument as well. The depth profiling was done by sputtering with argon at an acceleration voltage of $2.0 \mathrm{keV}$. AES was done using a $10 \mathrm{kV}, 10 \mathrm{nA}$ setting on the electron gun and multiplexed collection of the elements of interest. In AES, depth profiles were continued until the bare stainless steel surface was revealed. SEM image parameters are generally included as part of the image itself-typically the magnification is about $500 \mathrm{X}$.

A Kratos AXIS HSi XPS was used for the XPS measurements. Depth profiling for XPS was done by sputtering using argon ions accelerated to $4.0 \mathrm{keV}$. XPS was performed using the Magnesium anode at a power of $150 \mathrm{~W}(15 \mathrm{kV}, 10 \mathrm{~mA})$ and a pass energy of $40 \mathrm{eV}$.

The sputtering rate was calibrated using a 100 nanometer $\mathrm{SiO}_{2}$ film on a silicon wafer (Physical Electronics). Consequently, the depth profile units are reported in $\mathrm{SiO}_{2}$ Angstrom equivalents.

All five Vendor samples and the untreated coupon were subjected to AES depth profiling while XPS depth profiles were performed on Vendors B-E only.

AES depth profiles were analyzed using Physical Electronics' Multipak software while XPS depth profiles were analyzed using Kratos’ VISION software. 


\subsection{Results and Discussion}

\subsection{Scanning Electron Microscopy}

In the untreated coupon (Fig. 3-1), the tooling marks from the machining of the coupon are visible. The surface does not show much heterogeneity with regard to texture or morphology. Also visible is a "raster burn" square due to imaging at higher magnification.

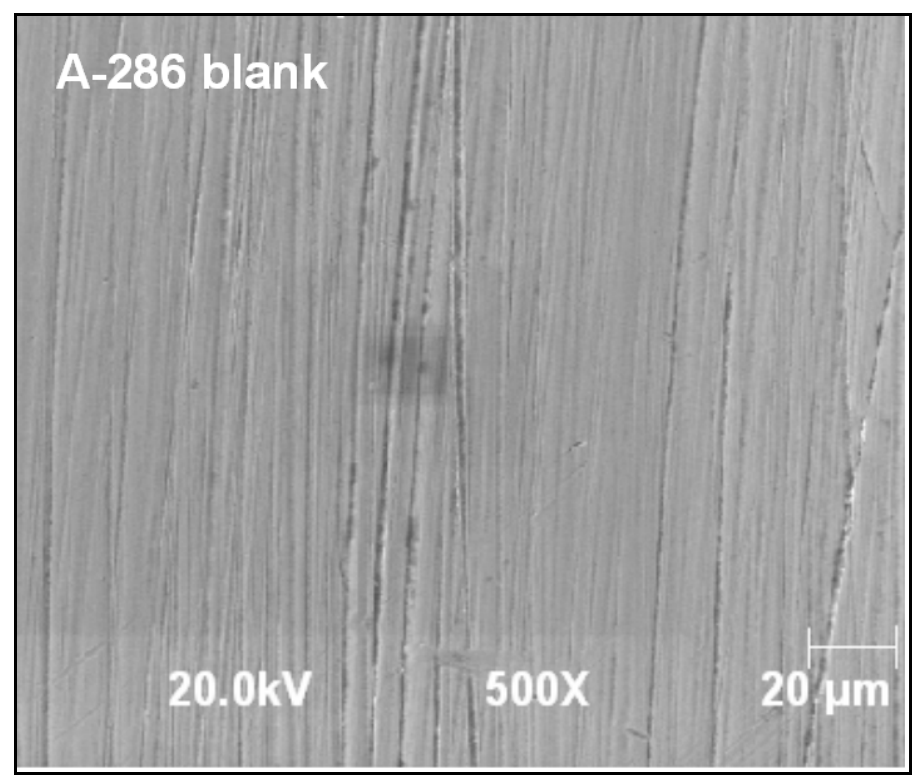

Figure 3-1. SEM image of untreated stainless steel coupon.

Vendor A (Fig. 3-2) shows a smoother appearance in terms of texture as the tooling marks are no longer visible. Apart from debris is visible on the surface, there is very little contrast on the surface, although this may be due to the low accelerating voltage for this image $(5.0 \mathrm{kV})$ compared to that of the untreated surface $(20 \mathrm{kV})$. 


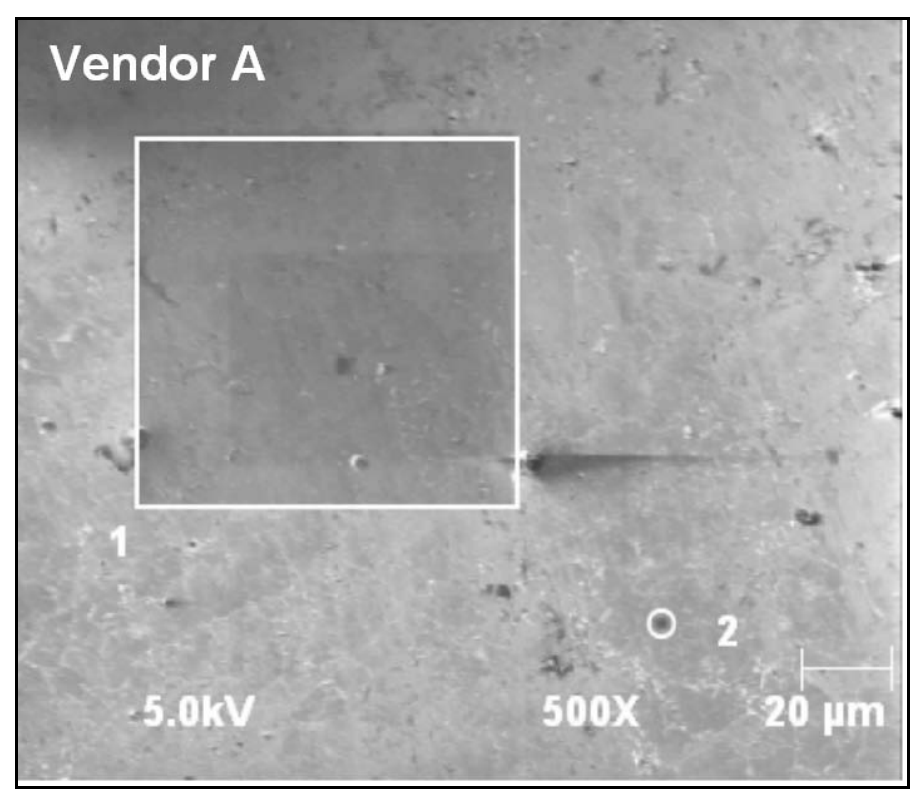

Figure 3-2. SEM image of Vendor A coupon.

Vendor B (Fig.3-3) shows a fairly smooth surface although the tooling marks are visible as slight contrast. Notable are black areas in the SEM image which are revealed to be composed of carbon by AES.

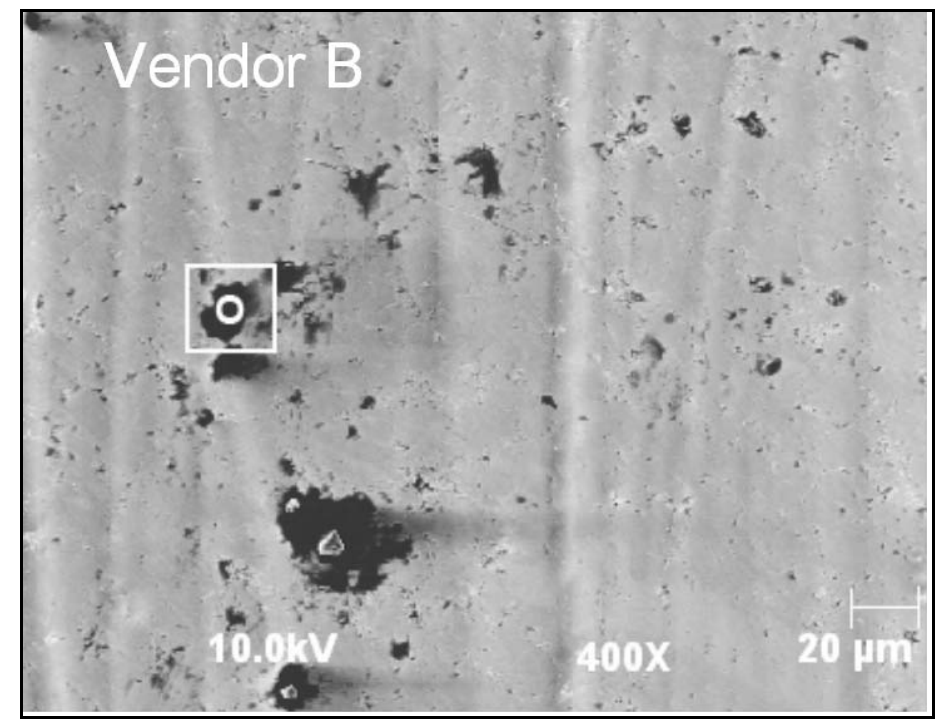

Figure 3-3. SEM image of Vendor B coupon.

Vendor C (Fig.3-4) treatment shows a light threadlike contrast which was not explored for elemental differences. The dark square is "raster burn" from previous imaging at higher magnification. 


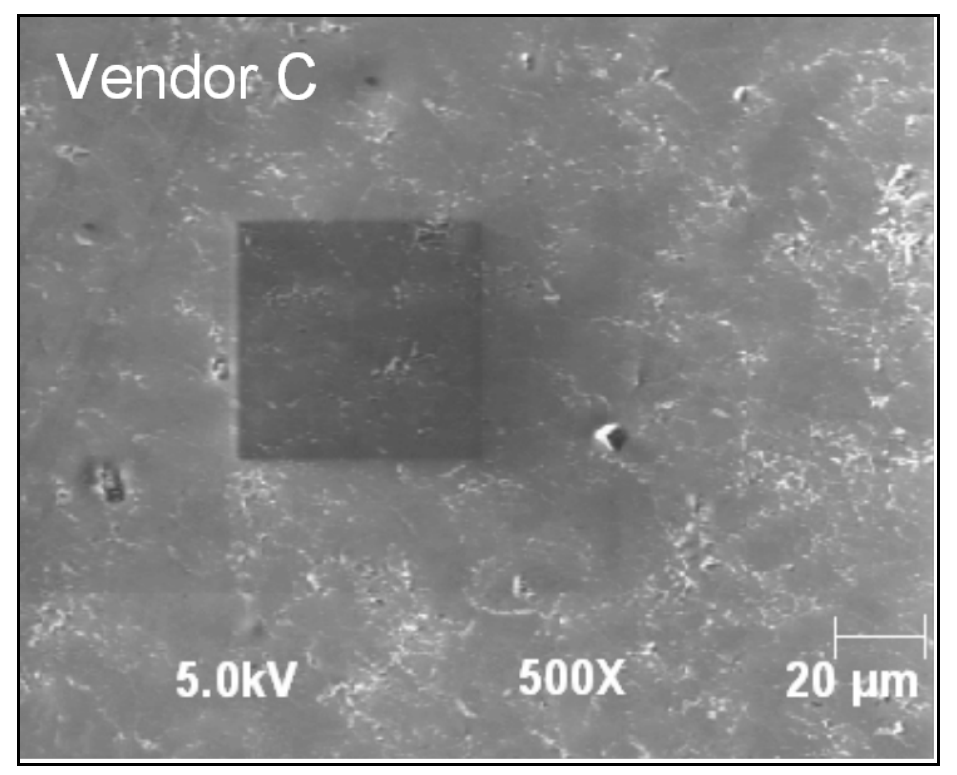

Figure 3-4. SEM image of Vendor $C$ coupon.

Vendor D (Fig. 3-5) shows a mountain range-like morphology, but the AES survey spectra of the two regions was not qualitatively different, and quantitative analysis of the survey spectra indicated that while the elemental composition of the mountain ranges and the smooth surfaces were virtually identical, the "mountains" had more Ca than the smooth surface, while the smooth surface contained more Fe (not shown).

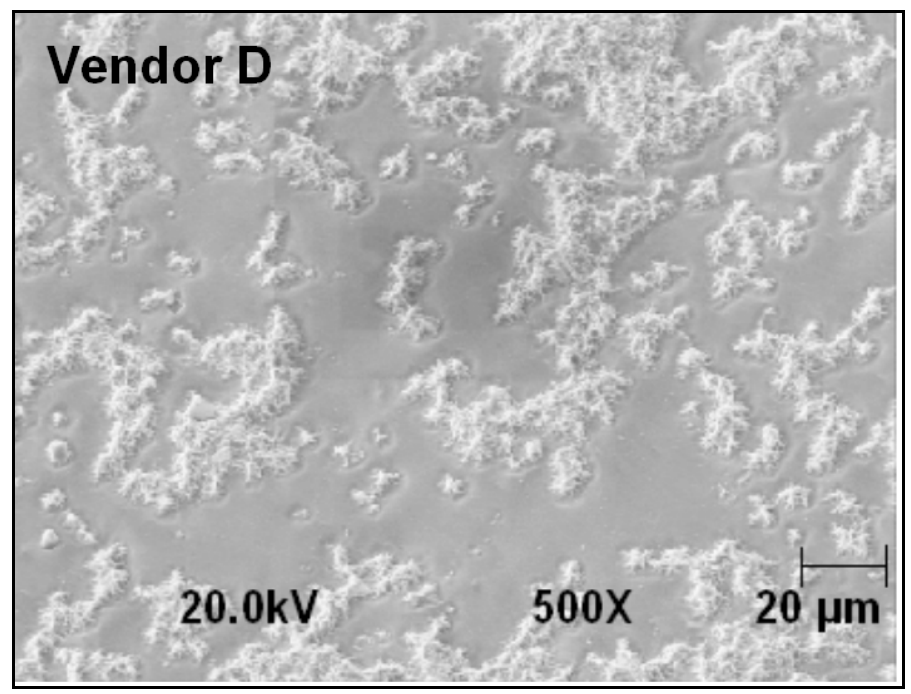

Figure 3-5. SEM image of Vendor D coupon.

Vendor E treatment (Fig. 3-6) shows a bumpy appearance which was not investigated, although it was noted that there was a hole in the surface coating on the coupon (Fig. 3-7), which revealed the uncoated metal beneath as confirmed by AES survey spectra (not shown). 


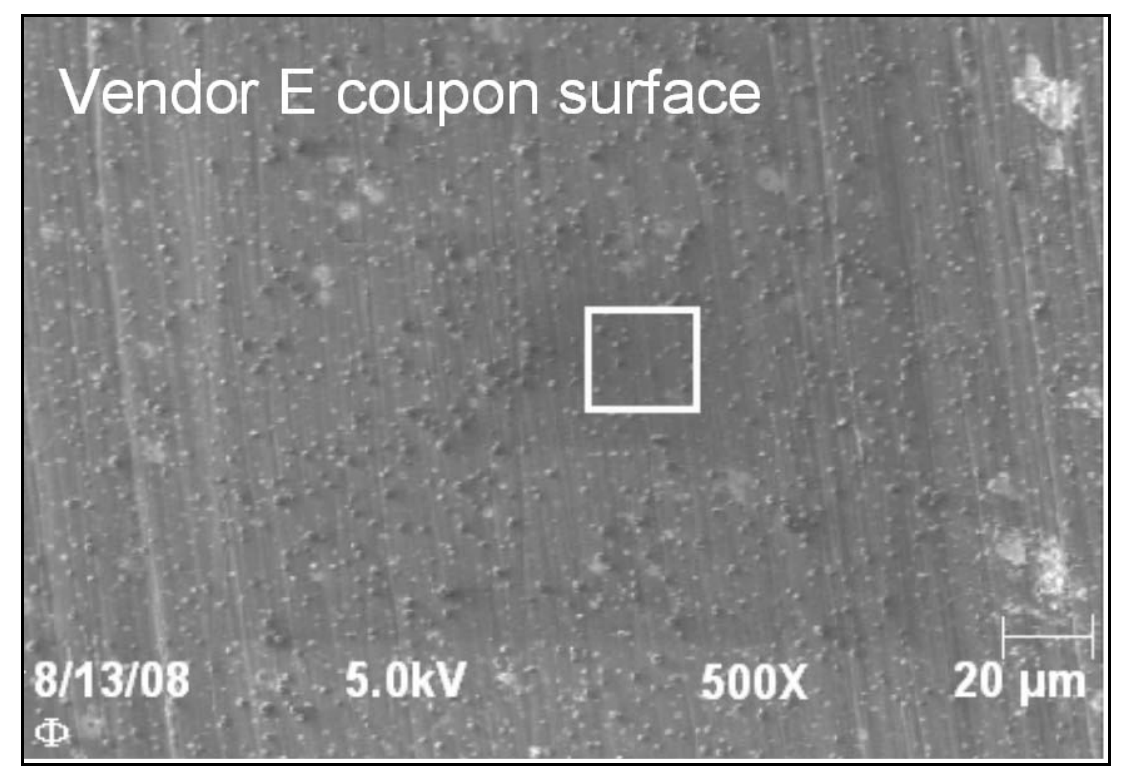

Figure 3-6. SEM image of Vendor E coupon.

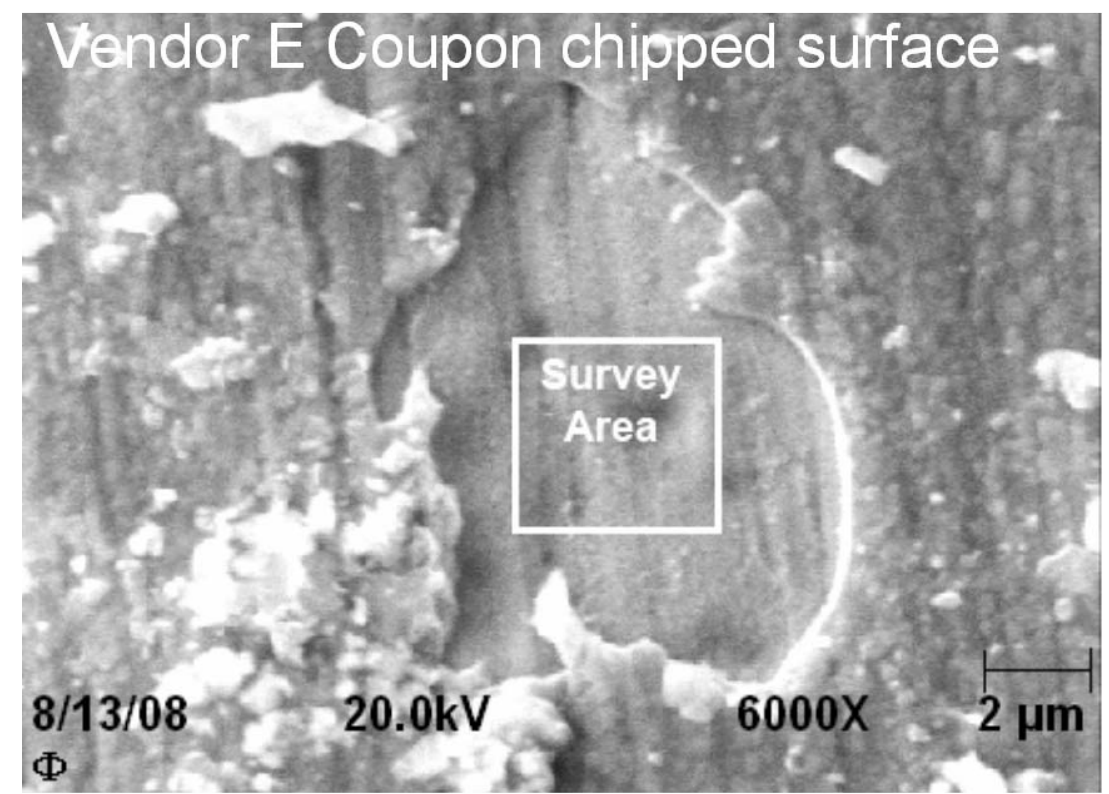

Figure 3-7. SEM image of Vendor E coupon showing chipped surface.

\subsection{Auger Electron Spectroscopy}

An AES survey spectrum of the unsputtered, untreated stainless steel surface is shown in Fig. 3-8. Before sputtering the surface is seen to be covered by adventitious carbon. Also apparent are $\mathrm{O}$, $\mathrm{Fe}$, and $\mathrm{Ni}$. 


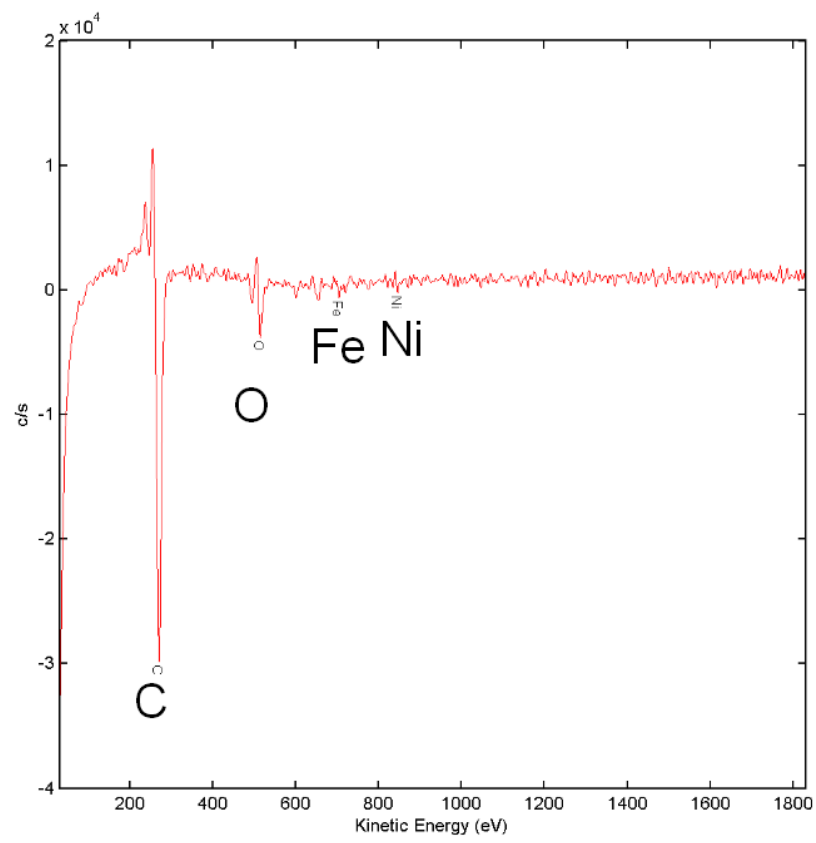

Figure 3-8 AES survey of the untreated stainless steel surface.

The untreated surface depth profile in Fig. 3-9 tracks C, O, Fe, Ni, and Cr. Carbon is present on the surface in all depth profiles. Carbon appearing on the surface of samples subjected to surface analysis is ubiquitous enough to be referred to as "adventitious carbon". The presence of oxygen is due to surface oxidation of the stainless steel which is irresponsible for the excellent corrosion resistance of stainless steels. The oxygen concentration rises to a maximum with depth and then declines continuously. The other components of the stainless steel, $\mathrm{Fe}, \mathrm{Cr}$, and $\mathrm{Ni}$, gradually rise throughout the depth profile until they reach bulk values (not shown). Another depth profile was taken of another spot on the same untreated sample and it was nearly identical (not shown). 


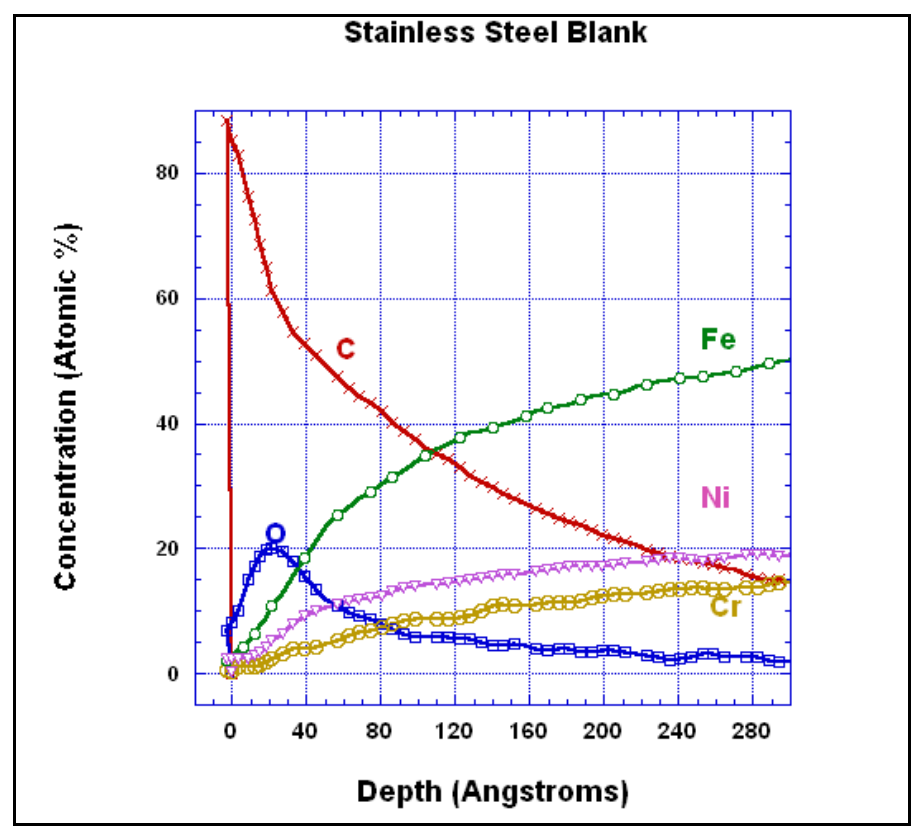

Figure 3-9. AES depth profile of stainless steel blank.

The Vendor A depth profile shown in Fig. 3-10 tracks the same elements as the untreated sample with the addition of $\mathrm{Zn}, \mathrm{S}$ and Ti. Ti, which is present in the bulk of stainless steel, is present at about 3 atomic \% consistently. Zn and S are present in the initial 50 Angstroms of the depth profile. Otherwise, the behavior of the elements in the untreated sample is similar to the untreated sample.

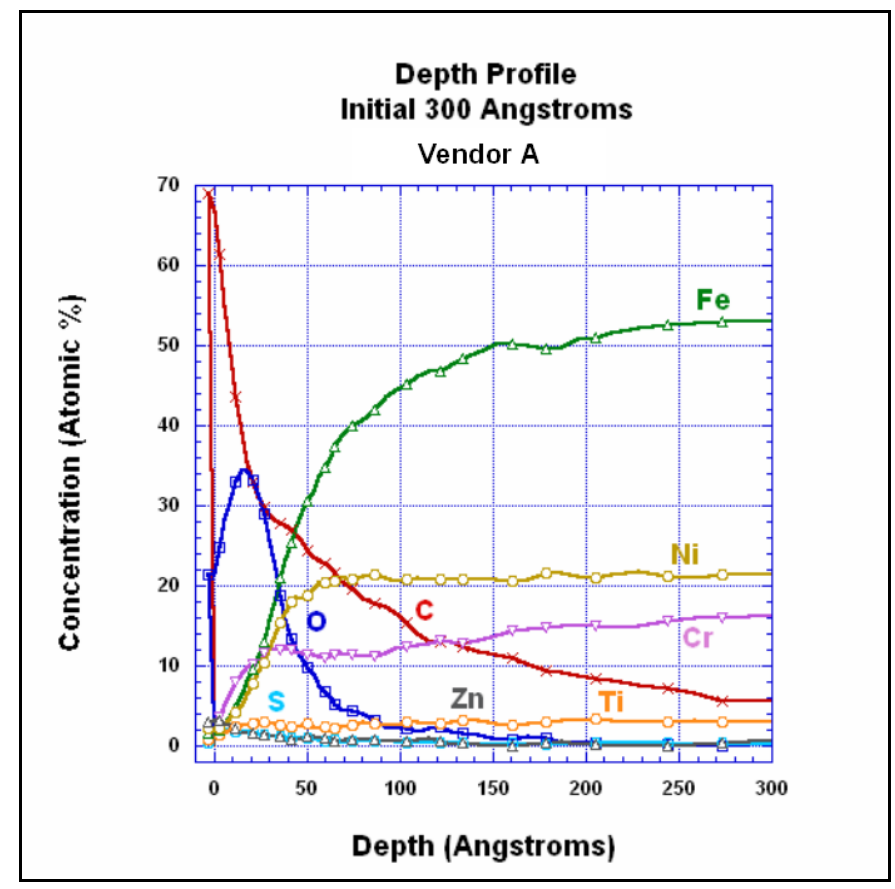

Figure 3-10. AES depth profile of Vendor A treatment.

The depth profile for Vendor B shown in Fig. 3-11 tracks the same elements as the untreated sample with the addition of $\mathrm{Ti}$ and $\mathrm{S}$. Ti is present throughout the depth profile at about $3 \%$, 
similar to the Vendor A sample. S appears at about 3\% similar to the initial 20 Angstroms of the depth profile. Again, the other elements follow the pattern of the untreated sample.

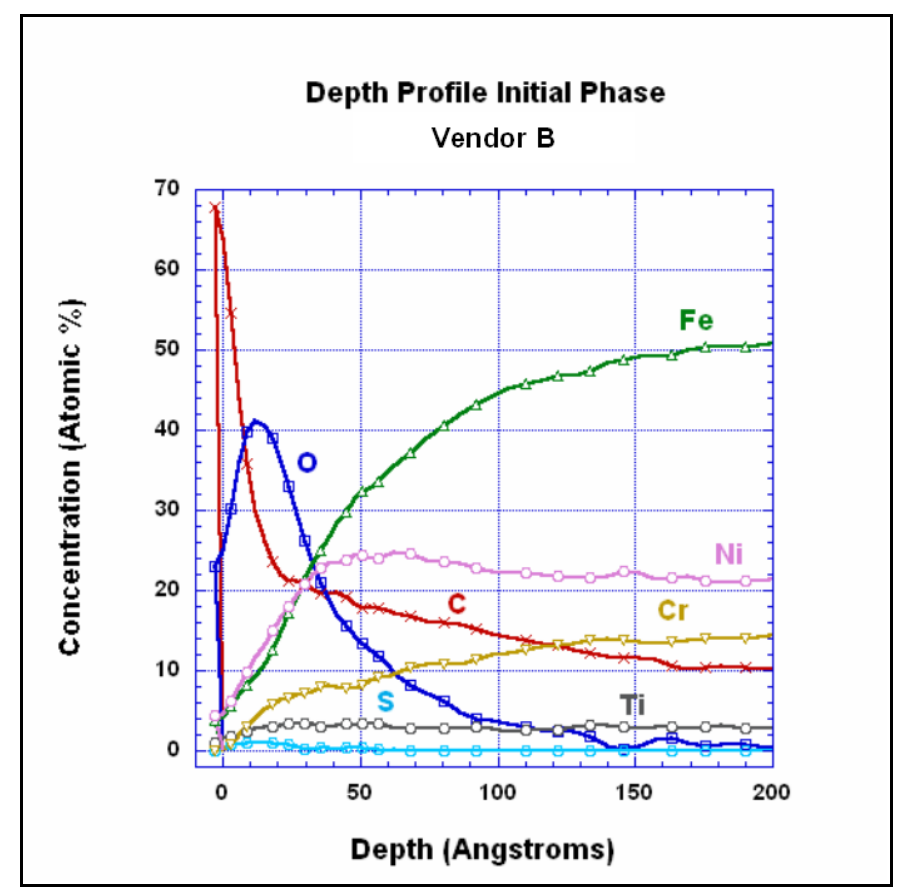

Figure 3-11. AES depth profile of Vendor B coupon.

Fig. 3-12 shows the depth profile of the Vendor $\mathrm{C}$ coupon where $\mathrm{N}$ appears, rising to $10 \%$ by 10 Angstroms and falling down to $4 \%$ at 40 Angstroms. Ti is present in the depth profile at about $3 \%$ similar to Vendors A and B surface treatments. The other elements are found to behave similarly to the untreated sample. 


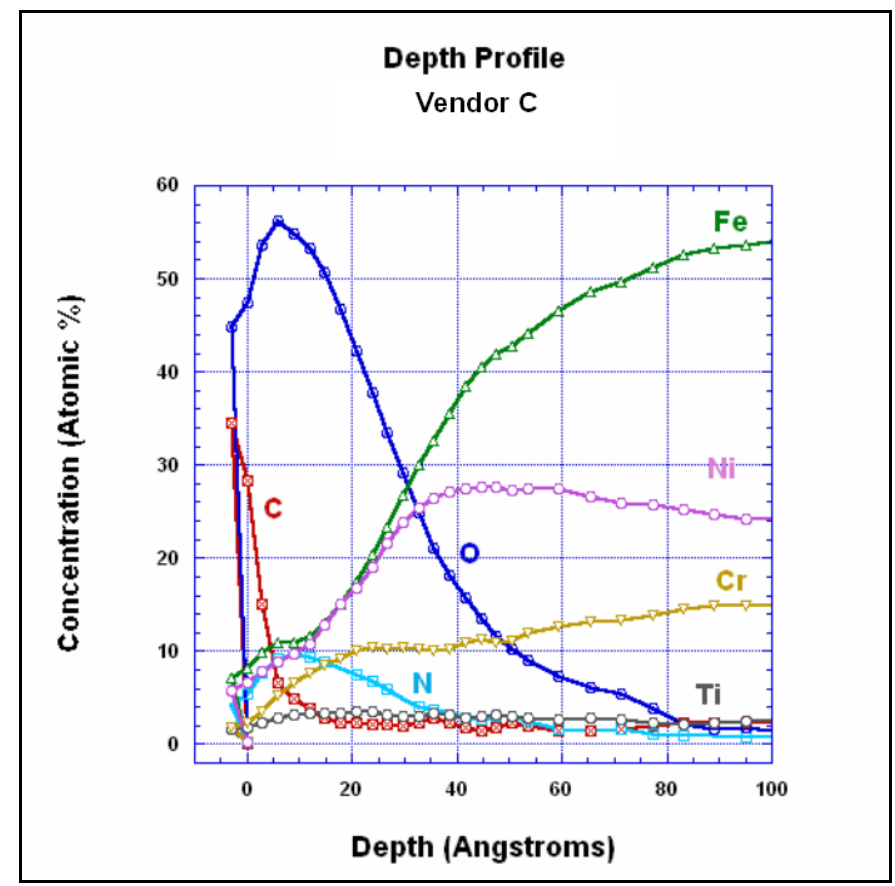

Figure 3-12. AES depth profile of Vendor $C$ coupon.

In the Vendor D coupon shown in Fig. 3-13, Ca is present at $7 \%$ at 10 Angstroms while its concentration drops to $4 \%$ at 50 Angstroms and continues to drop. $\mathrm{S}$ and $\mathrm{Cl}$ were present at $<1 \%$ in this sample. Ti is present in the depth profile, <1\% at first, but by 100 Angstroms it is about $3 \%$. The other elements in the sample are found to behave similarly to the untreated sample.

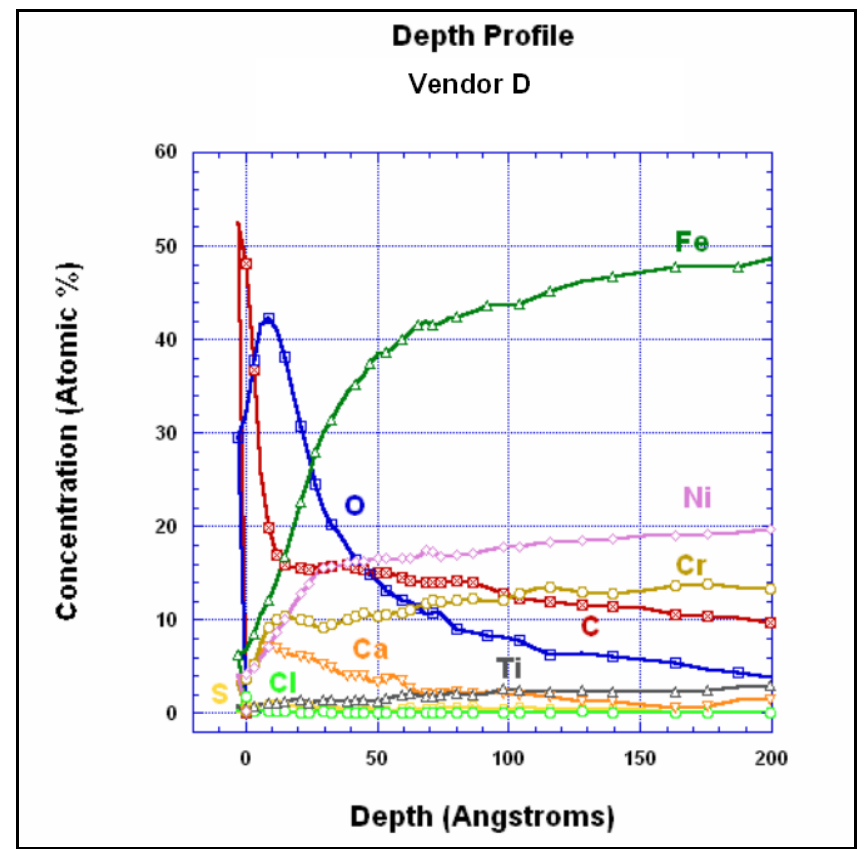

Figure 3-13. AES depth profile of coupon treated by Vendor D. 
The depth profile for the vendor E coupon shown in Fig. 3-14 is unlike the other surface treatments as it contains elemental silicon. The depth profile shows a nearly constant Si concentration of $95 \%$ for the first 1400 Angstroms of the depth profile, after which Si concentration drops and Fe rises, eventually to its bulk values (not shown). O rises to a maximum of 25\% at about 2600 Angstroms after which it drops dramatically. Cr and Ni start to rise at about 1600 Angstroms and eventually rise to their bulk values (not shown).

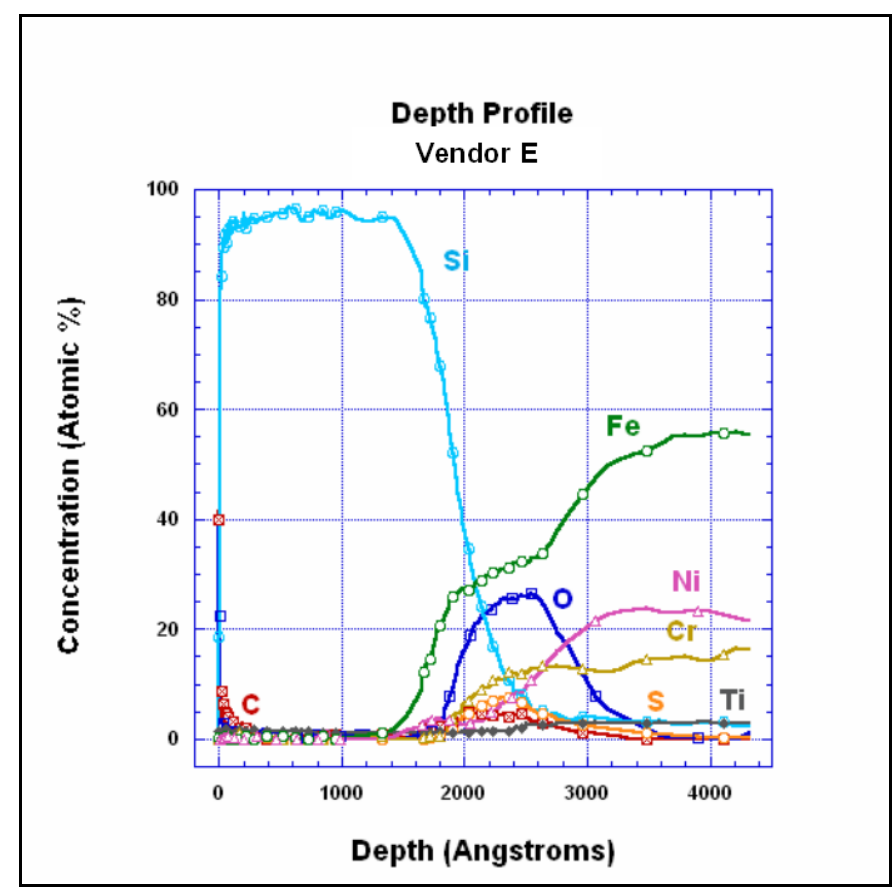

Figure 3-14. AES depth profile of coupon treated by Vendor $E$.

\section{3 $\underline{\text { Oxide thickness from AES depth profiles. }}$}

Oxide thicknesses were calculated from the AES depth profiles using a method similar to that used for determining sputter rates from a 1000 Angstrom $\mathrm{SiO}_{2}$ thin film on a $\mathrm{Si}$ wafer. The "rule of thumb" is that when the oxygen peak decreases to half its initial value, the interface between the oxide film and the silicon wafer has been reached. This has good basis in theory, and is a better approximation if the materials being sputtered have similar sputtering characteristics [1]. The $\mathrm{O}$ behavior from the AES depth profiles was used to determine these numbers. Basically, the value of Omax corresponds to the depth at which the O concentration maximized and the Omax/2 is the depth at which the $\mathrm{O}$ concentration reached half its maximum value. The difference of these two depths gives an approximate thickness of the oxidation layer, although the results are in $\mathrm{nm} \mathrm{SiO}_{2}$ equivalents, which correspond to the sputtering time. If the ratio of sputtering rates for $\mathrm{SiO}_{2}$ and the material being sputtered for the conditions in the depth profile are known, the actual physical dimensions of the oxide layer can be calculated. The sputtering rate ratios are unknown, so the results in this study are left in dimensions of linear (nanometer or Angstrom) $\mathrm{SiO}_{2}$ equivalents. These are also the units that both AES and XPS depth profiles are reported in. 
Table 2. AES depth profile oxide thickness calculation

\begin{tabular}{||l|r|r|r||}
\hline Sample & \multicolumn{1}{|l|}{ Omax (nm) } & \multicolumn{1}{l|}{ Omax/2 (nm) } & Thickness (nm) \\
\hline Untreated 1 & 2 & 6 & 4 \\
\hline Untreated 2 & 2 & 4.7 & 2.7 \\
\hline Vendor A & 1.5 & 3.7 & 2.2 \\
\hline Vendor B & 1.3 & 3.6 & 2.3 \\
\hline Vendor C & 0.6 & 3.1 & 2.5 \\
\hline Vendor D & 0.9 & 3.2 & 2.3 \\
\hline
\end{tabular}

\subsection{XPS depth profiles}

Shown following is an XPS survey of the Vendor C treated coupon sputtered down to bulk stainless steel (Fig. 3-15) as an example of the raw XPS data. The Ni 2p, Fe 2p, Cr 2p, C 1s, O 1s, and Ti 2p peaks were monitored.

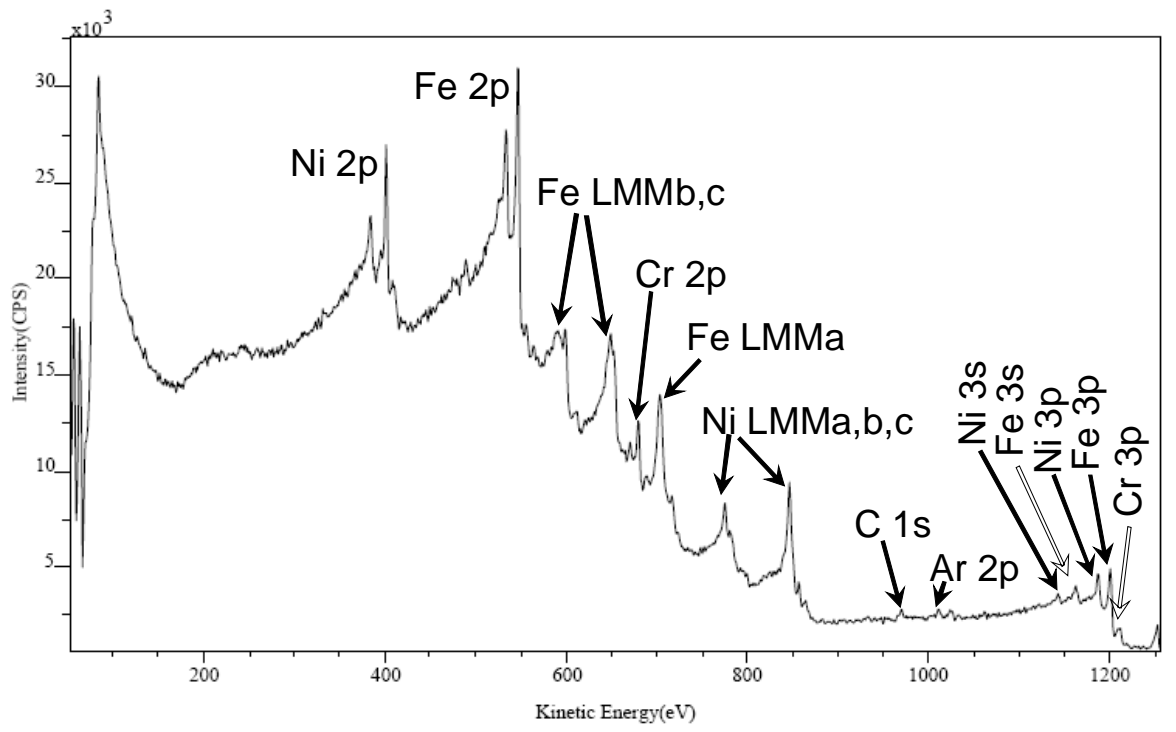

Figure 3-15. XPS survey of Vendor $C$ coupon sputtered down to bulk stainless steel.

Surface treatment by Vendors B, C, D, and E was investigated using XPS depth profiling.

Fig. 3-16 shows the XPS depth profile of the Vendor B sample treatment. Compared to the AES depth profile, the $\mathrm{Cr}$ in this depth profile behaves differently in that it rises to a more or less constant value after the first sputter cycle and stays there. S is not examined in this depth profile. Ti only appears after the first two sputter cycles and then was not present above background. The qualitative behavior of the other elements is similar to that seen for the AES depth profile. 


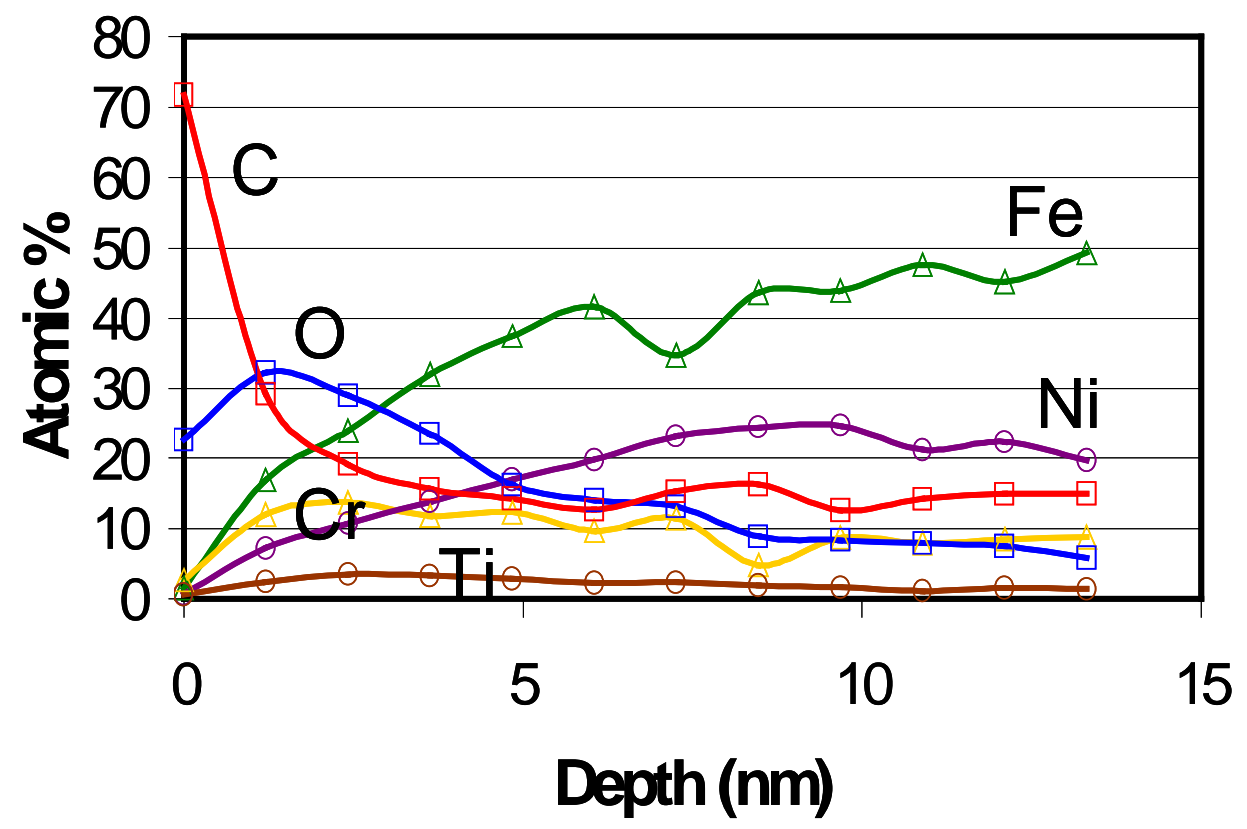

Figure 3-16 XPS depth profile of Vendor B treatment.

The XPS depth profile of the Vendor $C$ treatment is shown in Fig. 3-17. Compared to the AES depth profile, the $\mathrm{O}$ peak just declines rather than going through a maximum and then declining. $\mathrm{Cr}$ also behaves differently than in the AES profile, rising to a maximum of about $20 \%$ after the first sputter cycle and then decreasing eventually to a constant value of $10 \%$. Ti appeared only in the unsputtered sample and after the first two sputter cycles; after that it was not present above background. $\mathrm{N}$ was not followed in the XPS depth profile, but the other elements behaved similarly to the AES depth profile for Vendor C.

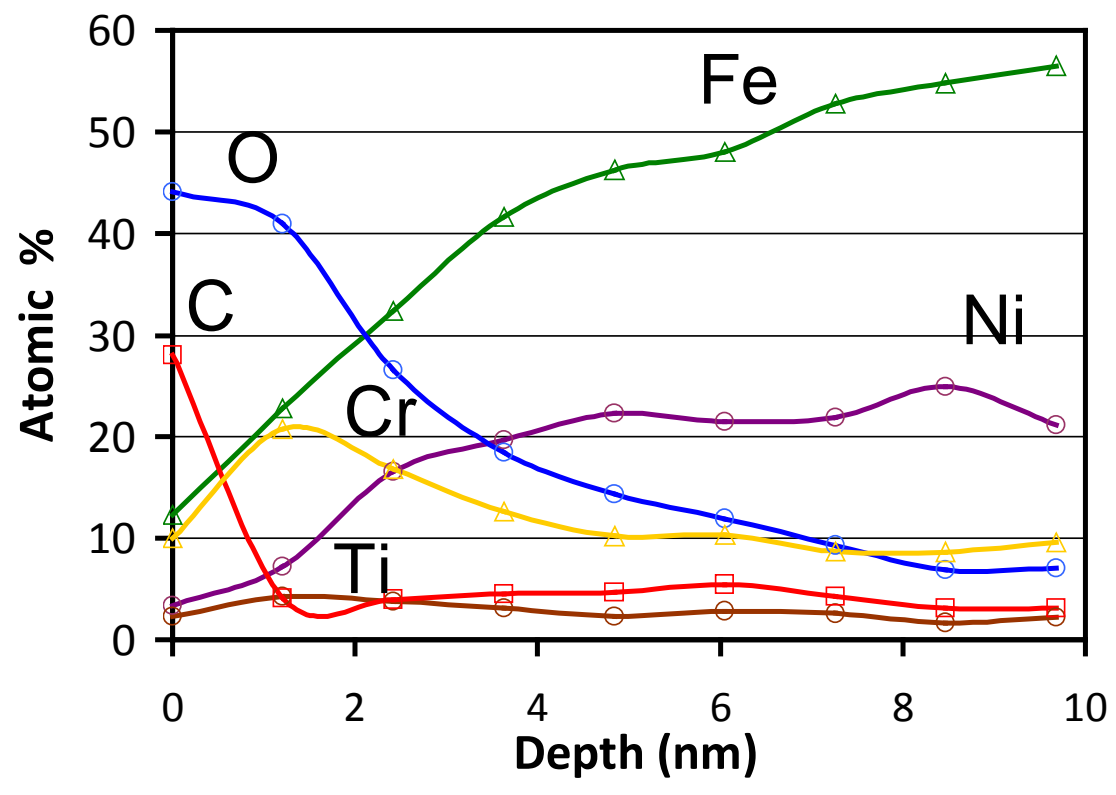

Figure 3-17. XPS depth profile of Vendor C treatment. 
The XPS depth profile for Vendor D is shown in Fig. 3-18. In contrast to the AES depth profile, $\mathrm{Ca}, \mathrm{Cl}$, and $\mathrm{S}$ were not measured. The $\mathrm{Cr}$ behavior in the XPS depth profile shows a peak after the initial sputter cycle and then declines to a constant value of about $10 \%$. The $\mathrm{O}$ does not peak but rather continually declines from $35 \%$ before sputtering to about $10 \%$ after about $5 \mathrm{~nm}$. Ti was not present above background. The other elements in the XPS depth profile behave very similarly to those in the AES depth profile.

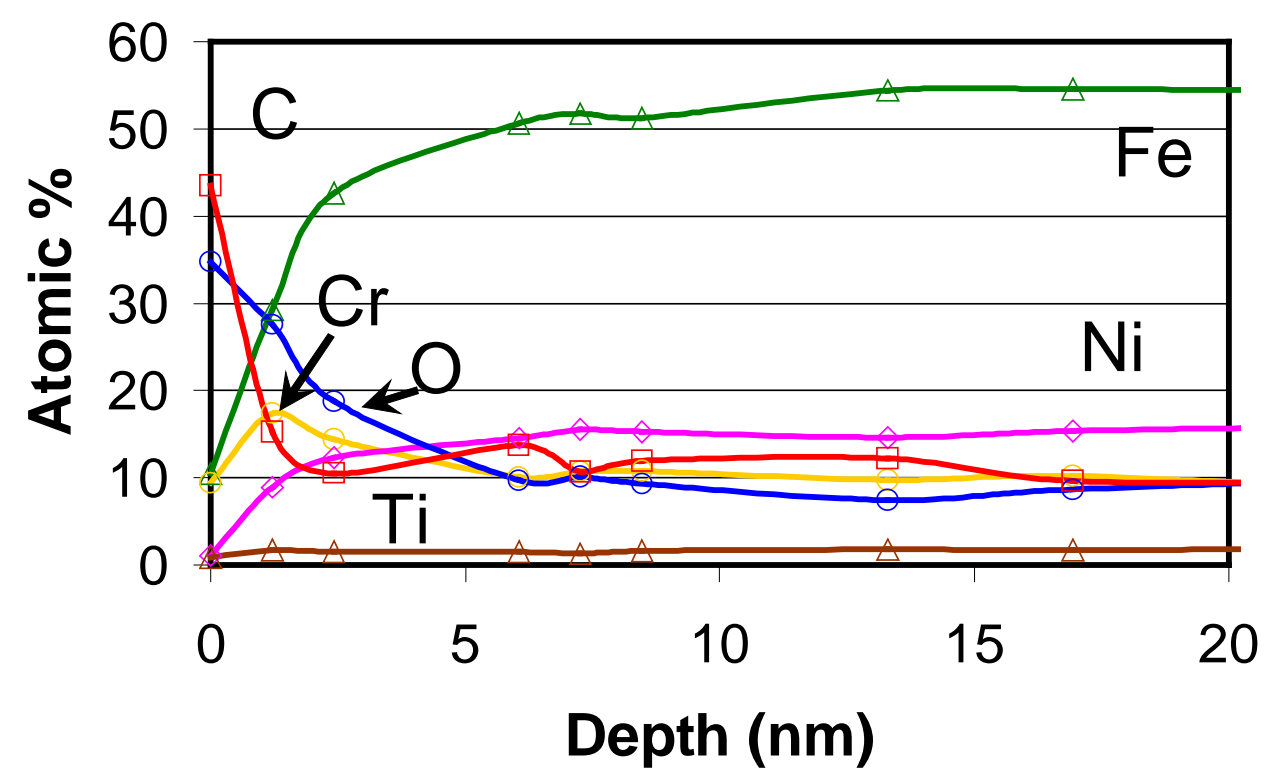

Figure 3-18. XPS depth profile of Vendor D treatment.

The XPS depth profile for Vendor E is shown in Fig. 3-19. Compared to the AES depth profile, the XPS depth profile did not show S, but otherwise the XPS depth profile is qualitatively very similar to the AES depth profile. 


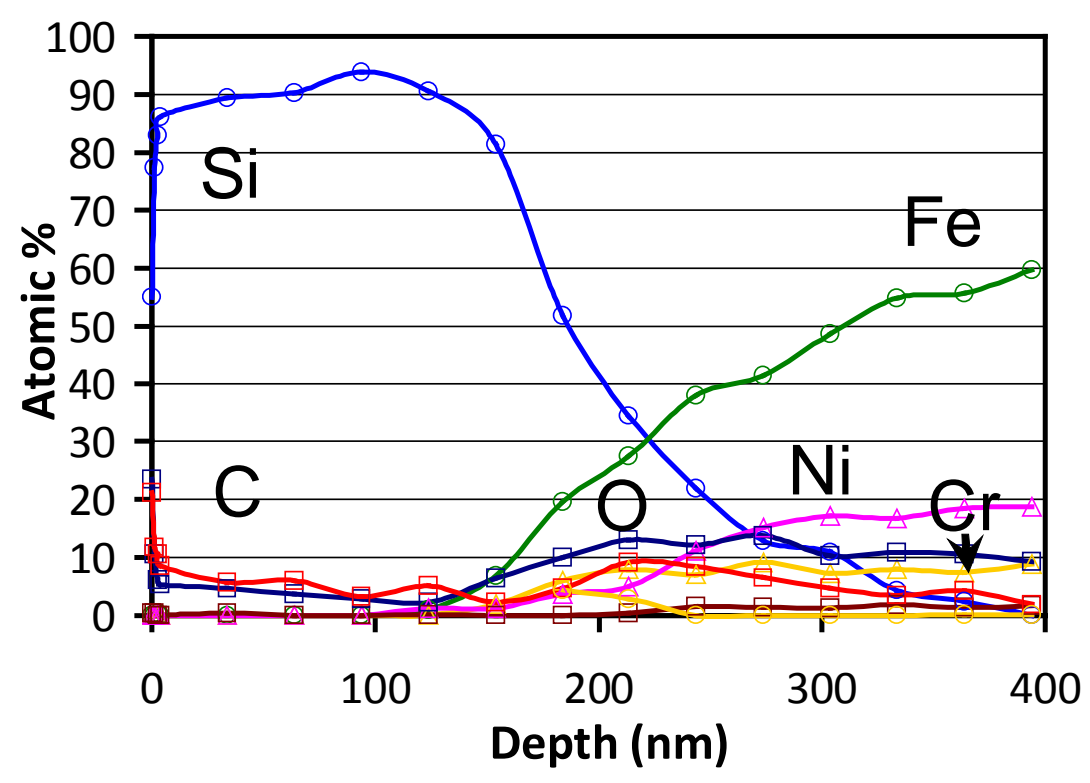

Figure 3-19. XPS depth profile of Vendor $E$ treatment.

Fig. 3-20 shows the $\mathrm{Cr} 2 \mathrm{p}$ spectrum as a function of sputter depth in $\mathrm{SiO}_{2}$ equivalents. XPS reveals the change in oxidation state of the $\mathrm{Cr}$ as a function of depth. This allows the identification of at least one constituent of the passivation layer as $\mathrm{Cr}_{2} \mathrm{O}_{3}$. Clearly at a depth of 0 and $1.2 \mathrm{~nm}$, the positions of the Cr 2p peaks are given by the black lines. By the $6 \mathrm{~nm}$ depth, the Cr $2 p$ peaks have clearly shifted to the positions given by the green lines. In between those positions, there appears to be a combination of those peaks. The black line positions are assigned to $\mathrm{Cr}_{2} \mathrm{O}_{3}$ while the green line positions are assigned to unoxidized $\mathrm{Cr}$ metal. 


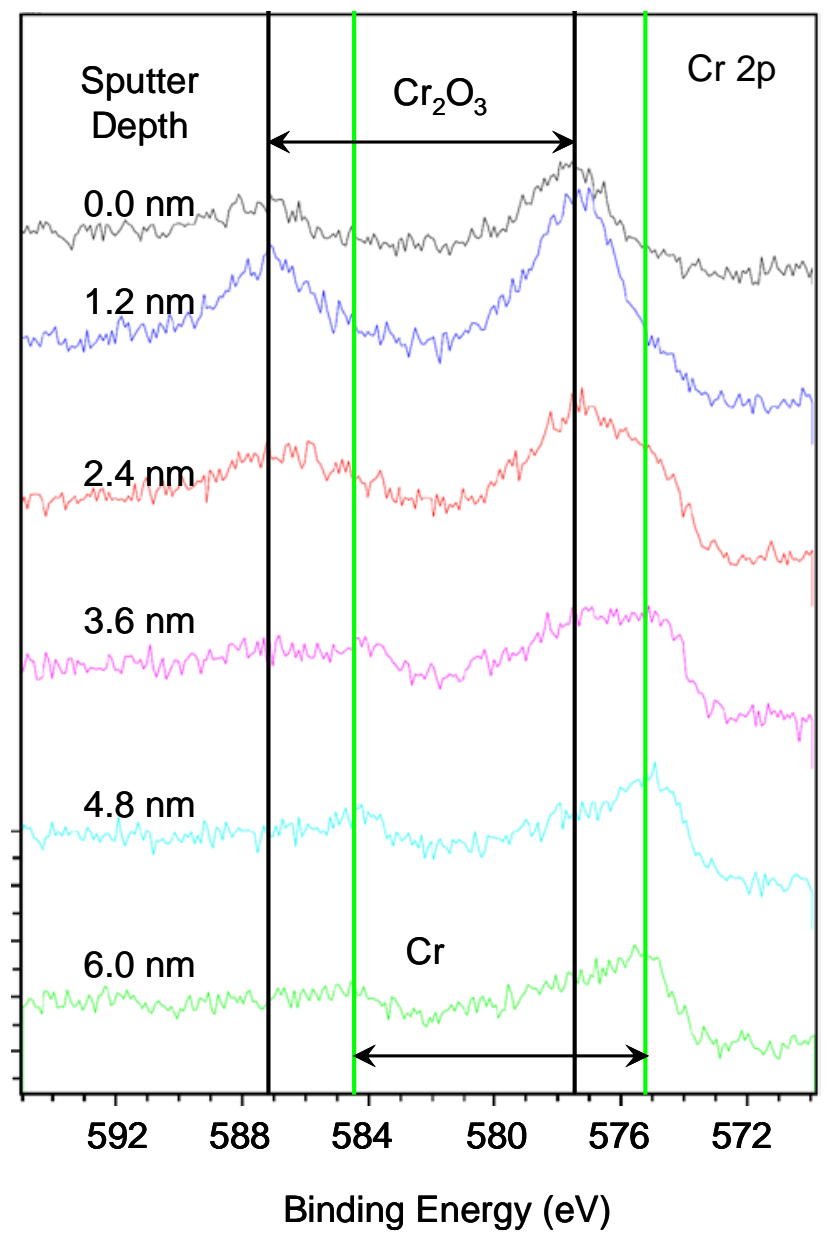

Figure 3-20. XPS depth profile of Vendor treated coupon showing change from $\mathrm{Cr}_{2} \mathrm{O}_{3}$ to $\mathrm{Cr}$ metal.

\subsection{XPS thickness calculations}

Calculations were performed on the Vendor B, C, and D samples using the XPS MultiQuant software package and the XPS data to determine the thickness of the $\mathrm{Cr}_{2} \mathrm{O}_{3}$ layer and the adventitious carbon layer above that. These calculations made several simplifying assumptions: that the surface was perfectly flat, the interface between the layers was atomically sharp, that the composition of each layer is pure, and that there are infinite layers over the analysis area. This model is a good approximation when the film morphology is flat without large features or impurities on the surface. This approximation is more valid for Vendors B and C samples with relatively smooth surfaces compared to the Vendor D sample, with its "mountains". The results are qualitative, as the errors in these calculations are often estimated at $20 \%$. However, these results are in actual physical units of the layers themselves rather than $\mathrm{SiO}_{2}$ equivalents. 
Table 3. Calculated adventitious carbon and $\mathrm{Cr}_{2} \mathrm{O}_{3}$ thicknesses for Vendors $\mathrm{B}, \mathrm{C}$, and D.

\begin{tabular}{|l|l|l||}
\hline Sample & $\begin{array}{l}\text { Thickness } \\
\text { Adventitious } \\
\text { Carbon (nm) }\end{array}$ & $\begin{array}{l}\text { Thickness } \\
\mathbf{C r}_{2} \mathbf{O}_{3} \text { (nm) }\end{array}$ \\
\hline Vendor B & 5.6 & 0.9 \\
\hline Vendor C & 1.8 & 0.9 \\
\hline Vendor D & 2.4 & 0.7 \\
\hline
\end{tabular}

\subsection{Conclusions}

Morphologically, all of the surface treatments studied here appear to change the surface morphology dramatically, as evidenced by lack of tool marks on the treated samples. Vendors A, $\mathrm{B}$, and C had relatively smooth morphologies, while Vendor D's surface treatment resulted in Ca rich "mountains" on the surface and Vendor E's treatment resulted in a bumpy surface that included at least one area that was missing from the coating, leaving the stainless steel exposed. It should also be noted that Vendor B's treatment appeared to leave large amounts of carbon on the surface, as evidenced by SEM (Fig. 3-4) and XPS calculations of adventitious carbon thickness (Table 3). In terms of the passivation treatment, Vendors A-D appeared to have oxide layers that were very similar in thickness to each other as well as the untreated samples (Table 2 and Table 3); although the untreated sample oxide layers appeared to be possibly larger. Vendor E's silicon coating appears to be on the order of $200 \mathrm{~nm} \mathrm{SiO}{ }_{2}$ equivalents thick. In terms of the chemistry of the coatings, they also appear very similar with some elements found in some AES depth profiles at very low concentrations that do not appear in others. However, at those low concentrations, these differences could be a result of sample handling.

\subsection{Recommendations, Path Forward or Future Work}

In the future, investigations of surface chemistry utilizing AES and XPS should primarily rely on AES as a depth profiling technique to determine the presence of elements and their depth distribution, as well as surface morphology due to the fast depth profiling ability of AES and its SEM capability. XPS should be used to identify the chemistry of the surface and near surface as AES cannot always give chemical state information while XPS can. The AES depth resolution could be further enhanced by rotation of the sample during sputtering. Furthermore, in the interest of expediency, compared to this investigation using XPS, the sputtering crater should be enlarged to increase the XPS signal-to-noise ratio and thus allow quicker or less noisy XPS spectra. The relevance of these observations on the vendors' various surface treatments is yet to be seen. 


\subsection{References}

[1] Surface Analysis by Auger and X-ray Photoelectron Spectroscopy, IM Publications SurfaceSpectra Limited, 2003. 
